\title{
ESCOLA, HOMOSSEXUALIDADES E HOMOFOBIA: REMEMORANDO EXPERIÊNCIAS NA EDUCAÇÃO FÍSICA ESCOLAR ${ }^{1}$
}

\author{
Vagner Matias do Prado ${ }^{2}$ \\ Arilda Ines Miranda Ribeiro ${ }^{3}$
}

\section{Resumo}

Ancorado nos estudos de gênero e teoria queer, o presente trabalho objetiva problematizar como a marcação social da homossexualidade é instituída por intermédio de práticas escolares da Educação Física. Apresentam-se relatos da realização de seis entrevistas semiestruturadas com jovens adultos, que se autorreconheceram como homossexuais, acerca de suas experiências em aulas de educação física. Os resultados permitem problematizar que as sexualidades não heterossexuais são estigmatizadas e inseridas em relações hierárquicas nas quais jovens homossexuais são alvo constante de manifestações de preconceito que negativizam suas expressões desejantes. A compreensão sobre algumas práticas corporais na perspectiva dicotômica do gênero, como as esportivas, reitera o processo de construção cultural das masculinidades e feminilidades, relegando às homossexualidades ao âmbito das “ininteligibilidades" sociais.

Palavras chave: Educação Física Escolar; Homossexualidades; Homofobia

\footnotetext{
${ }^{1}$ Apoio: FAPESP - Fundação de Amparo à Pesquisa do Estado de São Paulo

${ }^{2}$ Doutor em Educação. UNOESTE - Universidade do Oeste Paulista. Endereço: Rua Manoel Espinhosa, 570, Apto 05, CEP: 19050-440, Jardim Bongiovani, Presidente Prudente-SP, Brasil. Endereço eletrônico: vagnerprado@unoeste.br

${ }^{3}$ Professora Doutora Titular em História da Educação. FCT/UNESP - Universidade Estadual Paulista. Endereço: Rua Roberto Simonsen, 305, CEP: 19060-900 - Presidente Prudente-SP, Brasil.. Endereço eletrônico: arilda@fct.unesp.br
} 


\section{INTRODUÇÃO}

$\mathrm{O}$ artigo ora apresentado, resultante de uma pesquisa de doutorado, objetivou problematizar as marcações sociais de diferenças de gênero e sexualidade por meio de algumas práticas escolares da Educação Física ${ }^{4}$. Almejamos compreender de que maneira jovens, que se autodenominam homossexuais, representam a Educação Física e como tais práticas impactam em suas vidas. Inspirados em estudos de inclinação pós-estruturalista, estudos de gênero e teoria queer, para o presente propósito, apresentamos uma análise de seis narrativas geradas por intermédio da realização de entrevistas semiestruturadas com foco nas experiências vivenciadas por nossos colaboradores em aulas de educação física na educação básica.

\section{O CORPO COMO PRODUTO DISCURSIVO}

Além de apresentarem estudos que atestam a Educação Física como uma área transpassada por regulações de gênero e construção de modelos hegemônicos de masculinidade e feminilidade, José Devís Devís, Jorge Miguel e Andrew Sparkes (2005) fornecem indícios de que a heterossexualidade compulsória e a homofobia acompanham estudantes durante suas experiências nas aulas desse componente curricular. Relatam ainda que estudos sobre as relações entre sexualidade e práticas corporais são incipientes e necessitam ser estimulados "puesto que la ausencia de escritos, ya sean estos de investigación o de divulgación sobre la educación física, es más que evidente" (DEVÍS DEVÍS; MIGUEL; SPARKES, 2005, p. 83).

É através de nossos corpos que estabelecemos contato relacional com o mundo. Porém, nossa existência nada mais é do que um processo constante de materialização discursiva. Silvana Goellner (2010) se refere ao corpo na condição de um construto social erigido com base nos significados culturais a ele associados. Entretanto, não se trata de uma sobreposição do cultural sobre um dado da natureza, antes, um complexo processo de inter-relacionamento. "Em outras palavras: o corpo não é algo que está dado a priori. Ele resulta de uma construção cultural sobre a

\footnotetext{
${ }^{4}$ Quando nos referirmos à Educação Física como área de produção de conhecimentos e intervenção social grafaremos com iniciais maiúsculas. Ao referenciarmos as práticas pedagógicas escolares elaboradas proprofessores/as da área, grafaremos educação física com letras minúsculas.
} 
ESCOLA, HOMOSSEXUALIDADES E HOMOFOBIA: REMEMORANDO EXPERIÊNCIAS NA EDUCAÇÃO FÍSICA

ESCOLAR

qual são conferidas diferentes marcas oriundas de diferentes tempos, espaços, conjunturas econômicas, grupos sociais, étnicos etc." (GOELLNER, 2010, p. 73).

Tentar garantir uma existência biológica como a única linha de "explicação" sobre os corpos é uma tarefa complicada. Judith Butler (2002) esclarece que não é possível conceber o sujeito anterior a um contexto discursivo. Ou seja, um agente que possa garantir, a partir de seus atos, a existência de uma unidade interior, naturalmente constituída. Para a perspectiva pósestruturalista a "matéria" não pode ser significada sem a existência cultural, pois a aparente verdade biológica sobre os corpos nada mais é do que um efeito linguístico que estrutura determinadas, para não dizer homogêneas, possibilidades de existências. "Donde existe un "yo" que anuncia o habla produciendo así un efecto en el discurso, existe de antemano un discurso que precede y posibilita esse "yo"” (BUTLER, 2002, p. 57).

É a partir dessa perspectiva que compreendemos a construção social do masculino ou feminino e das expressões de sexualidade. $\mathrm{O}$ gênero e a sexualidade são aqui tomados como discursos que produzem o que julgam apenas descrever. A partir da ação política de nomeação "isto é um menino" ou "este é um homossexual" o discurso inaugura a possibilidade cultural para a leitura de determinados corpos. As bases linguísticas constituintes das práticas corporais também acionam o processo de fabricação dos sujeitos a partir da dicotomização de gênero e sexualidade. As adequações existentes entre atividades corporais de "meninos" ou "meninas" se constituem em linhas de captura que reiteram o posicionamento social dos corpos e instituem hierarquizações nas quais o feminino será considerado como inferior ao "lido" como viril.

\section{A HETEROCONSTRUÇÃO DOS SUJEITOS POR INTERMÉDIO DAS PRÁTICAS CORPORAIS}

A investigação realizada aponta que durante aulas de educação física na escola, corpos lidos como "não masculinos" ou "homossexuais" acionam práticas de discriminação que intencionam negativizar posições de sujeitos não pautadas na ótica heterossexual.

Pesquisador: Pensando nos momentos das aulas de educação física, mesmo no período em que você não se reconhecia enquanto homossexual, você 
PRADO, V. M.; RIBEIRO, A. I. M.

recorda de alguma situação na qual houve algum indício de discriminação por conta da sua aparente diferença?

Sujeito4: Foi como eu te disse, mais nas aulas de futsal mesmo que os meninos não deixavam eu jogar e quando deixavam era aquelas piadinhas bobas de colocar eu como goleiro para eu poder "pegar nas bolas" e tal, ou sempre me colocavam só para fazer número, ou seja, se precisasse. No interclasse precisava de um número " $x$ " para poder participar, então as vezes, quando não tinha mais ninguém, eu tava ali só para fazer número mesmo, volume, para eles poderem participar.

Durante aulas de educação física na escola os corpos que não se adéquam ao modelo de masculinidade tomado como regra são rechaçados e marcados negativamente para que possa ser reconhecido pelo grupo como "não apropriado". As chacotas, piadas e brincadeiras que visam subjugar o "outro", como demonstrado na fala de nosso interlocutor, visibilizam o quanto algumas situações ocorrentes nas aulas constroem a representação abjeta do sujeito homossexual ou que não performatiza uma masculinidade próxima da considerada aceitável. É nesse sentido que Priscila Dornelles (2013) afirma que a Educação Física é uma disciplina escolar que deve ser problematizada no sentido de questionar que corpo se pretende formar e como a escola constrói mecanismos reguladores para que tal objetivo seja alcançado.

Esses argumentos nos auxiliam a compreender o relatado por nosso colaborador. Frente a uma prática esportiva predominantemente associada ao universo masculino, a presença de um sujeito que não expresse a masculinidade padrão compartilhada por determinado grupo aciona mecanismos de marcação de diferenças sociais que tendem a rechaçá-lo e registrar seu não pertencimento a determinado contexto. O sujeito construído como "diferente" passa então a ser policiado e, não raro, proibido de acessar espaços comuns ao grupo. Caso sua presença seja "necessária", motivada por algum interesse maior, como completar o número de jogadores de um time para que o jogo ocorra, a tolerância ${ }^{5}$ é instaurada, mas que essa seja constantemente marcada pela abjeção que materialize a diferença do sujeito para com seu grupo. Durante a entrevista o mesmo colaborador continua sua rememoração narrativa:

\footnotetext{
5 A noção de "tolerância" não remete a pensar em "reconhecimento". O ato de tolerar é uma tentativa de inferiorização do outro, pois, como "sou melhor" tolero o "diferente", mesmo ao não reconhecer sua existência como possível. Tolerar é uma convivência forçada com as diferenças.
} 
ESCOLA, HOMOSSEXUALIDADES E HOMOFOBIA: REMEMORANDO EXPERIÊNCIAS NA EDUCAÇÃO FÍSICA

ESCOLAR

\section{Pesquisador: E como você se sentia? \\ Sujeito4: Eu me sentia um pouco desprezado, ficava triste, mas assim, nunca pensei em levar o problema nem para minha mãe, nem para a diretoria da escola. Sempre, sempre aquilo foi comigo mesmo, sempre guardei pra mim.}

A marcação social da diferença de gênero ou sexualidade, por carregar valores e atributos negativos frente a uma vivência que fuja da (ou ao menos que desestabilize a) norma possui um efeito significativo no processo de subjetivação dos sujeitos. Isso tanto para os que acionam as regras de demarcação identitárias, quanto para os que são marcados a partir desse ritual linguístico. Os que acionam esse mecanismo reiteram as normas que regulam os corpos (inclusive os seus) a partir dos ideais do gênero e sexualidade. Já os que são marcados presenciam sentimentos de tristeza, vergonha, não pertencimento, não sendo "bem vindos" em determinados espaços. No caso de nosso colaborador, a tristeza, o sentimento de desprezo e a impotência perante tais situações marcaram, de maneira significativa, as experiências educativas nas aulas de educação física. Como representar a escola como espaço formativo uma vez que as experiências possibilitadas nesse contexto são pautadas por sentimentos negativos e que, inclusive, não possibilitam construir redes de apoio frente a situações de coação?

É possível sacar vestígios de que a Educação Física, historicamente, contribuiu para a reprodução da heterossexualidade a partir da implementação de seus conteúdos. Para além de uma mera "reprodução", acrescentaríamos que ela se estruturou com base nas normas regulatórias do gênero e no "pensamento heterossexual" fundantes de suas bases "filosóficocientíficas".

Rodrigo Rosa (2008) nos demonstra o quanto a relação entre esporte e homofobia está presente na produção acadêmica da Educação Física. $\mathrm{O}$ autor propôs uma reflexão sobre como essa relação era abordada pela produção de conhecimento. Analisou os trabalhos acadêmicos divulgados na Revista Brasileira de Ciências do Esporte (RBCE), os anais dos Congressos Brasileiros de Ciências do Esporte (CONBRACE) e os anais dos Congressos Nacionais de História do Esporte, Lazer, Educação Física e Dança (CNHELEFD) no período compreendido entre 1979 a 2007. Em um universo amostral de mais de 6.000 produções encontrou apenas três referências acerca da homossexualidade. 
PRADO, V. M.; RIBEIRO, A. I. M.

Visto que a produção de conhecimentos é uma das condições para que profissionais possam planejar suas intervenções, as aulas de educação física nas escolas podem ser estruturadas a partir de (des)conhecimentos que subjugam qualquer forma de atuação que não se adeque aos padrões de comportamento pré-estabelecidos. Nesse sentido, não raro, sujeitos que transgridem as regras de gênero e/ou sexualidade compreendidas como "normais" acabam estigmatizados e sofrem as consequências de mecanismos de discriminação, tais como o heterosexismo e a homo, lesbo ou transfobia. Em conversas informais com sujeitos que se autorrepresentavam como gays e lésbicas sobre suas relações com a Educação Física, Luciene Santos (2008) relata que a disciplina se configurava como um terreno de conflitos sobre sexualidades no qual esses/essas jovens nem sempre se saiam bem. Para muitos/as deles/as, essas experiências criaram aversão pelas práticas esportivas.

Experiências não tão prazerosas instituídas a partir das relações estabelecidas entre homossexuais no contexto escolar também apareceram em nossa investigação. O disfarce de situações de preconceito e discriminação a partir da representação de "brincadeiras" pode ser reconhecido como uma estratégia de banalização de violências que acometem jovens homossexuais nesses espaços.

Pesquisador: Em relação a época do colégio, você já teve algum problema relacionado à questão da sexualidade?

Sujeito5: Então, no colégio, não só o meu, mas provavelmente o de várias pessoas, sempre tem aquelas brincadeirinhas. Ainda mais quando, sei lá, ainda mais quando você não quer... ainda mais quando no caso, geralmente, homossexuais, geralmente fazem mais amizades com mulheres, daí os moleques já ficam meio que zoando, falando um monte, entendeu? Igual na educação física, se por acaso você não quer jogar alguma modalidade, geralmente eles já ficam em cima, falando por que você não quer, essas coisas, entendeu?

Em outras relações estabelecidas, quando não da exclusão, os estudantes que conseguiam se inserir nas práticas acabavam fazendo através de uma "inversão" do tipo de atividade. Ou seja, homens (gays) no voleibol, e mulheres (lésbicas) no futebol de salão, mas não escapavam das chacotas dos colegas de turma. Possivelmente "este modelo de Educação Física ampliava os problemas na escola, porque explicitava ou reforçava a dinâmica de atribuição de papéis 
ESCOLA, HOMOSSEXUALIDADES E HOMOFOBIA: REMEMORANDO EXPERIÊNCIAS NA EDUCAÇÃO FÍSICA

ESCOLAR

masculinos ou femininos" (SANTOS, 2008, p. 18). Como, em alguns contextos, o voleibol é representado como uma prática "feminina", quando da participação do sujeito homossexual nas aulas este deve se adequar a tal atividade.

Pesquisador: E qual a reação dela [professora] frente a essa negativa de jogar futebol?

Sujeito1: Não, em relação ao futebol ela deixava eu jogar vôlei, por exemplo. Porque, normalmente, os moleques iam todos jogar futebol. Eu, e mais alguns meninos e as meninas, quase todas, iam jogar vôlei.

A inserção de nossos colaboradores em grupos compostos por meninas também possibilita inferir que, muitas vezes, por não demonstrarem habilidades reconhecidas pelos meninos como "masculinas", procuram alternativas para aderirem a prática do esporte. Em alguns casos, quando da participação de meninas em determinadas atividades, a competitividade exacerbada perde força e favorece a integração de estudantes homossexuais nas aulas.

No que se refere a mediação do/a professor/a frente a uma situação de preconceito e discriminação, torna-se preocupante a omissão estabelecida. Seu posicionamento pode contribuir para legitimar a violência homofóbica nos espaços escolares.

Pesquisador: Em relação a uma intervenção do professor de educação física frente a essas situações de perseguição, de violência durante as aulas, ou de proibir com que você fizesse alguma atividade, o próprio grupo de alunos, teve alguma intervenção dos professores? Os professores viam, percebiam essa situação?

Sujeito4: Acho que intervenção para solucionar o problema nunca houve. Houve assim, o professor chega nos alunos: "ah, deixa ele jogar, ele também sabe". E até ali eu acho que os meninos deixavam eu jogar pela figura do professor. Mas para intervir e solucionar o problema, nunca ouve.

A omissão pedagógica por parte dos professores/as de Educação Física frente a situações de discriminação contra o considerado "diferente" se configura em um eixo formativo passível de ser problematizado. A não intervenção docente em momentos nítidos de preconceito de gênero e sexualidade acaba por reiterar que a heterossexualidade e os comportamentos hegemônicos de 
PRADO, V. M.; RIBEIRO, A. I. M.

gênero são os únicos a serem considerados válidos. Essas práticas são ferramentas que constroem a homofobia e a utiliza como "pano de fundo" para tecer as ações "educativas" escolares.

Pesquisador: E frente a esses conflitos, qual era a reação do professor? Sobre essas ofensas, quando isso surgia?

Sujeito2: Ai... pra mim ele nunca foi a frente... Pra mim ele não fazia nada mesmo. Ficava sentado com o apito lá e, nessas partes, ele não fazia.

Existem vários relatos que apontam que a Educação Física se constitui como o espaço escolar de maior discriminação. Para muitos, o professor foi o mediador responsável pelo afastamento de homossexuais das práticas esportivas, dentro e fora da escola. Segundo Carlos da Cunha Júnior e Victor de Melo (1996), situações como essas demonstram que não é o homossexual que não gosta de praticar as atividades, ao contrário, são os inúmeros mecanismos homofóbicos criados, os responsáveis por esse afastamento.

Sujeito6: Eu odiava educação física. Assim, em termos... Eu gostava de ficar muito no pingue-pongue, na mesa de pingue-pongue. Tinha uma mesa na escola. Mas ela queria que eu jogasse vôlei... E não gosto de futebol, e ela pegava no meu pé para eu jogar futebol. Eu não gostava de jeito nenhum. Evôlei também não era minha praia.

Ao professor/a de Educação Física cabe problematizar que o afastamento de determinadas práticas se refere, em muito, aos medos e receios de uma exposição que possa contribuir para o estigma e rechaço social de estudantes LGBTTI ${ }^{6}$ s, vulnerabilizando-os/as frente ao grupo. A atuação docente deveria estar preparada para intervir frente a essas situações, pois, obrigar o estudante a participar de determinada atividade, ou "ameaçar" os dissidentes com possíveis medidas punitivas como, por exemplo, atribuir notas baixas aos estudantes que não querem realizar determinadas práticas, não se configura em uma medida efetiva que contribua para a reconstrução dos significados atribuídos pelos estudantes às práticas corporais vivenciadas na escola. Esse fato pode gerar, inclusive, a construção de experiências negativas e o afastamento das atividades corporais.

\footnotetext{
${ }^{6}$ Lésbicas, Gays, Bissexuais, Travestis, Transexuais e Intersexuais.
} 
ESCOLA, HOMOSSEXUALIDADES E HOMOFOBIA: REMEMORANDO EXPERIÊNCIAS NA EDUCAÇÃO FÍSICA

ESCOLAR

Pesquisador: (...) existiam alunos que não participavam das aulas?

Sujeito5: Existia. Mesmo os professores sempre frisavam: "quem não participar vai reprovar". (...). Sempre tinha os alunos que participavam uma vez no mês, sempre inventava desculpa para ir embora.

Pesquisador: E qual a reação da professora, além de falar? Qual era a atitude dela em relação a esses alunos que não faziam as aulas?

Sujeito6: Ela sempre dava nota zero. Era isso. Era a única coisa. Ela falava: "é zero, é zero". Muita gente eu já vi levar zero, zero, zero porque não queria participar da educação física. Eu no começo era assim, eu não queria participar. O primeiro zero que eu levei eu comecei a participar. Mesmo não querendo (...)

A representação negativa sobre a homossexualidade por parte dos professores/as também deve ser problematizada enquanto um produto de suas formações. Em sua pesquisa Francis Madlener (2006) denuncia a falta de discussões aprofundadas sobre a construção cultural das sexualidades durante o processo de formação dos estudantes. Embora estes citem que temáticas como homossexualidade, diversidade sexual e preconceito foram abordados em algumas disciplinas, bases epistemológicas que contribuíssem para repensar a sexualidade enquanto uma dimensão cultural/discursiva, não se fizeram presentes. Assim, representações negativas acerca da homossexualidade, caso não sejam problematizadas durante a formação inicial e/ou continuada, podem ser utilizadas enquanto base para uma futura atuação profissional. Em nossa investigação, isso se explicita.

Pesquisador: Você recorda de alguma situação com os professores que você categorizaria, ou reconheceria como uma situação de preconceito? Sujeitob: Não, de frente não. Mas, tipo assim, igual quando eles estavam com raiva, igual, esse era um amigo meu que ele não participação das educação física, então, quando ele [professor] ficava com raiva que ele [amigo] não queria fazer, queria que todo mundo participasse que era obrigatório... até teve uma época que eles colocaram na escola "é obrigatório a participação na educação física"... ai tipo, eles falavam: "ai, aquele viado... É um viadinho que não quer saber de nada". Tipo assim, e 
PRADO, V. M.; RIBEIRO, A. I. M.

você ouvia e a gente, no meu caso, eu ficava com um pouco de medo daí eu participava mais (...)

Pesquisador: e esses comentários partiam dos professores ou dos... [interrupção pela resposta do sujeito]

sujeito6: Dos professores.

Dessa maneira cabe perguntar: que tipo de relação esses/essas professores/as estabelecem com os estudantes LGBTTIs? Quais os impactos gerados nesses sujeitos a partir das injúrias e xingamentos oriundos dos próprios "profissionais da educação"?

É evidente que problemáticas referentes ao gênero e a sexualidade comumente surgem no trabalho pedagógico do/a professor/a de educação física. Entretanto, como já dito, reflexões sobre essas relações nem sempre aparecem durante os espaços de formação inicial desses profissionais. E quando a temática aparece durante a formação? Seria esta capaz de sensibilizar futuros professores e professoras para o assunto?

Essa foi a questão norteadora da pesquisa de Luciene Santos (2007) com um grupo de 17 professores/as para identificar a opção por terem cursado ou não uma disciplina eletiva denominada "Gênero e co-educação na Educação Física" e se esta repercutiu em suas ações na escola. Os/as professores/as participantes da investigação, independente do fato de terem ou não cursado uma disciplina específica sobre gênero e coeducação, são uníssonos quando questionam que esse tipo de formação deveria perpassar todo o currículo formativo da graduação na área.

Dos estudantes entrevistados que optaram pela disciplina, alguns justificaram essa escolha pelo fato de intencionarem obter recursos pedagógicos que os auxiliassem em uma atuação "adequada" sobre a temática do gênero na escola. Sobre os sujeitos que não a cursaram, estes se ancoravam na ideia de que, na época de suas formações, não focavam a escola como futura área de atuação profissional.

$\mathrm{Na}$ primeira justificativa percebe-se que o termo gênero parece não alertar os/as profissionais de que não se trata de um “instrumento para implementarem suas práticas". Não o compreendem como um processo de formação e adequação cultural no qual os próprios professores/as se encontram ancorados.

Nesse sentido, Marcelo Moraes e Silva (2008) argumenta que mesmo ao demonstrarem certo discurso desconstrutivo acerca de qualidades "masculinas" ou "femininas" em suas narrativas, muitos professores/as acionam o imperativo da diferença sexual ao afirmarem que, 
embora modeladas pela cultura, há uma base biológica que determinaria e evidenciaria a diferença entre homem e mulher. Para o contexto educacional, e acrescentamos aqui para a Educação Física, "o sexo é [ainda] a base conceitual determinante e delineadora das ações (hetero)normativas forjadas na escola" (DORNELLES, 2013, p. 117).

O segundo ponto a ser destacado remete a uma falsa aproximação de que essa reflexão só se aplicaria ao contexto escolar. Com isso, o gênero parece ser utilizado enquanto um "apêndice pedagógico" exclusivo da escola, sendo que para outros espaços de atuação profissional em educação física, o conhecimento sobre o gênero não seria "aplicável".

Todavia, regulações corporais que levam em consideração os mecanismos reguladores dos gêneros e sexualidades quando da atuação em educação física se fazem presentes em ambientes escolares ou não. Em situações de iniciação ou treinamento esportivo, por exemplo, essas regulações se mostram ativas como aponta um de nossos interlocutores:

Pesquisador: Você chegou a falar que participou de várias turmas de treinamento, de escolinhas de esporte, desde criança. Nesses outros espaços, na prática desses outros esportes fora da escola, você chegou a sofrer algum tipo de preconceito, ou presenciar algum preconceito direcionado a outro amigo, outra amiga?

Sujeito2: Ah, tinha... Sempre tinha comentários de mim que: "ah, ele é meio afeminado".

Pesquisador: Ecomo você se sentia nessas situações?

Sujeito2: Ah, ao mesmo tempo desconfortável. Mas como era mais velho eu me sentia inserido no grupo deles, entendeu? Tipo assim, de eles falarem... mas não toda vez é lógico, de ser ofendido toda hora não, mas é, tipo assim: "Ah seu viadinho, chega ai não sei o que" sabe, tipo. É.. mais, tipo, tá jogando e falar: "A seu viado, pula" sabe, esse tipo de... que eu falei pra você, que a gente era chamado mais.

Durante espaços de formação em educação física as discussões sobre gênero realmente parecem ser estabelecidas em paralelo com reflexões sobre a escola. Embora seja necessária essa aproximação, ela não se torna eficaz para pensar um processo de formação no qual a categoria gênero também se relaciona com questões de atividade física e saúde, desempenho esportivo, lazer, estética etc. Um exemplo é que a maior parte das pesquisas sobre Educação Física e gênero 
PRADO, V. M.; RIBEIRO, A. I. M.

instituem a escola enquanto cenário analítico. Seria a ideia de formação apreendida nos curso de Educação Física unicamente escolar? A academia de musculação/ginástica/pilates/ioga/dança, as escolhinhas de iniciação esportiva, os grupos de recreação em clubes, hotéis ou acampamentos, ou o treinamento de alto rendimento não seriam espaços sociais constituídos e constituintes dos gêneros?

Alguns relatos gerados em nossa investigação demonstram que, mesmo em contextos nos quais as atividades eram realizadas fora do cenário escolar, discriminações sobre uma suposta homossexualidade foram relatadas. Corroborando com as reflexões de Rosa (2008, 2010), nota-se que o esporte é fortemente transpassado pelo dispositivo da homofobia, sendo os/as profissionais de Educação Física responsáveis pela mediação dessas atividades, partícipes no processo de manutenção dessa forma de violência. Devido à banalização da homofobia, muitas situações de chacotas, xingamentos e perseguições não são compreendidas como violência, sendo realocadas ao universo da "brincadeira".

Pesquisador: Dentro desses outros espaços de práticas de esportes, de atividades físicas fora da escola, você recorda de alguma situação de preconceito?

Sujeito2: No basquete mais, porque no basquete tinha [homossexuais]... Mas era mais velho, eu não tinha contato. No treino, assim, era feito por ano. Eu lembro que o meu era 88/89 e ai eu treinava junto com os mais novos, e os mais novos não perturbavam muito, sei lá, por eu ser maior assim. Mas eu nunca fui também de dar orelha, não sei. Mas tinha no outro grupo maior que zoava com a gente sabe... Mais é, zoavam assim. Falavam que eu era bichinha, tal. Mas falava pra todos e eu achava que era uma brincadeira meio normal, entendeu?

No que se refere ao/a professor/a, é notório que a banalização da homofobia a partir de sua formatação em piadas ou "brincadeiras" pejorativas acompanha esses/essas profissionais desde os tempos da formação inicial. Em uma investigação sobre as representações sociais de estudantes de Educação Física, Marcelo Victor da Rosa (2004) constatou que representações negativas e preconceituosas sobre a homossexualidade permeavam o processo de formação desses sujeitos que, inclusive, afirmaram que o tema não aparecia de forma contextualizada durante a formação. Rosa identificou duas formas pelas quais a homofobia se fazia presente no 
ESCOLA, HOMOSSEXUALIDADES E HOMOFOBIA: REMEMORANDO EXPERIÊNCIAS NA EDUCAÇÃO FÍSICA

ESCOLAR

cotidiano universitário: a homofobia velada, referente ao distanciamento de homossexuais ou sujeitos que aparentavam "ser", mais presentes nas narrativas de recém-ingressos na universidade; e a homofobia transfigurada na forma de brincadeiras, esta com ocorrência na fala de todos os sujeitos investigados.

A pesquisa de Santos (2008) também relata que professores e professoras atuantes na educação básica demonstraram dificuldades em compreender as artimanhas e alcances da homofobia. Na descrição da fala do professor "João", participante de seu estudo, é visível o quanto a própria homofobia (ou a aversão de ser comparado à homossexuais) é utilizada enquanto uma "estratégia pedagógica" que se vale da conotação jocosa para com a homossexualidade: “[...] uma briga a gente fala com qualquer um 'oh seu viado!' não sei o que, sabe como?" (SANTOS, 2008, p. 86). Segundo a pesquisadora "esta banalização é perigosa porque reforça este tipo de preconceito, cristaliza a concepção de que se trata de uma manifestação indesejada e forja subjetividades homofóbicas.” (SANTOS, 2008, p. 86).

Nas escolas a relação entre políticas de normalização e esportes também pode instituir o rechaço para com estudantes que transgridem os dito "padrões", sejam eles referentes ao gênero, sexualidade, constituição corporal ou estética. Muitas vezes, jovens que não se encaixam no perfil instituído acabam capturados pela discriminação, sendo a exclusão desse meio uma das táticas utilizadas para reestabelecer a ordem rompida, e a autoexclusão, talvez, uma estratégia para não se visibilizar.

Pesquisador: E em relação a esses alunos que não participavam [das aulas de educação física]?

Sujeito5: tinha as meninas, tinha menina que não gostava de esporte de jeito nenhum. Principalmente as mais gordinhas assim. $E$ os meninos também, um pouco fora dos "padrões" [frisou aspas com os dedos], tinha meio que vergonha, sabe, de jogar as coisas.

Pesquisador: E como você se sentia durante essas aulas? [em decorrência da falta de habilidade]

Sujeito6: Muito mal. Era mais ou menos assim, eu preferia ficar estudando, tá com o livro na mão, do que ter meu tempo livre pra mim. Tipo, era como se falava, era uma diversão, né. Era um tempo livre que você tinha pra treinar, pra você. Mas eu não, eu preferia ficar com o livro. 
PRADO, V. M.; RIBEIRO, A. I. M.

No que tange às práticas esportivas, a marcação social de diferenças de sexualidade e a construção da homofobia também fazem constantes aparições. Em muitos casos, a compreensão dos esportes enquanto um cenário predominantemente masculino, viril e heterossexual se encarrega de subjugar qualquer forma de expressão que abale essa ideia. É preciso compreender que:

\begin{abstract}
No ambiente esportivo contemporâneo, a homofobia, de maneira difusa e diversificada desempenha papel fundamental no dispositivo de controle dos corpos e das sexualidades, contribuindo para o estabelecimento de espaços e práticas sociais diferenciados tanto para quem se adéqua à matriz heterossexual hegemônica quanto para quem se desvia dela (ROSA, 2010, p. 199).
\end{abstract}

Um caso recente que demonstra essa estreita relação entre esporte e homofobia foi o ocorrido com o meio de rede Michael dos Santos da equipe do "Vôlei Futuro" durante um jogo pela SuperLiga em 2011. No primeiro jogo da semifinal, realizado em Contagem-MG contra a equipe SADA/Cruzeiro, o atleta passou a ser hostilizado por toda a torcida adversária: "Foi um ato de preconceito, realmente. Estou acostumado com a pressão de torcida, mas nunca com um ginásio inteiro, inclusive mulheres e crianças me chamando de "bicha" o jogo todo" (LANCENET, 2011).

Em uma tentativa de desestabilizar a equipe paulista, a torcida adversária elegeu como alvo a possível homossexualidade de um de seus jogadores. A homossexualidade se tornou o foco para depreciações e tentativas de marcação de uma diferença instituída por uma racionalidade machista e homofóbica. É interessante notar que a homofobia, tal qual o gênero, se constitui em uma linha de subjetivação normalizadora, pois não somente homens, mas "mulheres e crianças" a utilizam enquanto mecanismo heterossexista que visa legitimar a heterossexualidade no meio esportivo enquanto única forma legítima de expressão. O que caberia perguntar é: qual a importância da revelação forçada da homossexualidade no que se refere ao desempenho atlético de determinado profissional? A resposta que conseguimos hipotetizar nos remete ao preconceito.

A homofobia também se faz presente no esporte através dos testes de feminilidade adotados pelo Comitê Olímpico Internacional (COI) quando da dúvida sobre o sexo de determinadas atletas. Com o aumento do número de mulheres que ascendiam ao esporte e, de certa forma, o questionavam enquanto um espaço predominantemente masculino, a implantação 
ESCOLA, HOMOSSEXUALIDADES E HOMOFOBIA: REMEMORANDO EXPERIÊNCIAS NA EDUCAÇÃO FÍSICA

ESCOLAR

de mecanismos que garantissem que essas não seriam "homens disfarçados" se torna necessária. Segundo Fabiano Devide e Sebastião Votre (2005), a preocupação foi tanta que em 1966, durante o campeonato europeu realizado em Budapeste (Hungria), a Federação Internacional de Atletismo Amador (FIAA) determinou que todas as atletas desfilassem nuas perante um corpo médico constituído por três ginecologistas, antes que obtivessem permissão para competir.

Para a ótica analítica por nós adotada, os testes de feminilidade e a preocupação com o doping em mulheres atletas nada mais são do que estratégias heteronormativas que visam a manutenção da divisão sexual enquanto "provas naturais" do macho e da fêmea. Entretanto, se faz interessante notar que, até para esse meio, a "diferença sexual", anatomicamente atestada, passa a ser questionada enquanto prova da "verdade" sobre os gêneros. Assim, é preciso lançar mão de tecnologias cada vez mais capazes de invadir a "essência" dos sujeitos para revelar suas "identidades" como, por exemplo, os testes cromossomiais e os que identificam a utilização de substâncias anabólicas.

Para além do cenário esportivo, em alguns casos, a simples presença de uma mulher atlética aciona o dispositivo de vigilância e alerta em relação à transgressão de gênero. Como argumenta a teórica queer Judith Halberstam (2008) por esta razão, a "mujer atleta se convierte, casi inevitablemente, en el objeto de una intensa vigilancia y observación de género" (HALBERSTAM, 2008, p. 81). Ao rechaçar a representação de fragilidade ou inatividade atribuída ao "feminino", essas sujeitas, não raro, são imediatamente relacionadas à lesbianidade. Embora essa seja apenas uma das múltiplas configurações da sexualidade, é certo que esse aprisionamento identitário intenciona subjugar e estigmatizar a construção corporal da mulher na contramão do preconizado pelas políticas normativas do gênero.

O padrão de comparação esportiva sempre foi masculino. Dessa maneira, quando uma mulher demonstra uma performance superior ou quando quebra algum recorde, não raro, acaba por ter sua "feminilidade" questionada uma vez que tais desempenhos seriam "impensáveis" para o gênero feminino. Esse mesmo pensamento transpassado pelo dispositivo do gênero aloca os atletas homossexuais a uma condição secundária no esporte de alto rendimento. Uma vez que questionam a masculinidade, não pode ser admissível que estes sejam reconhecidos por suas qualidades atléticas. 
PRADO, V. M.; RIBEIRO, A. I. M.

\section{ALGUMAS CONSIDERAÇÕES}

É notório que as marcações sociais de diferenças de gênero e sexualidade por intermédio das práticas pedagógicas da Educação Física instituem relações conflituosas e, por vezes, pautadas por práticas de violência que passam a atingir a integridade, tanto física quanto social, dos sujeitos considerados como "diferentes". É necessário problematizar de que maneira, e ancorado em que tipo de conhecimento, esse componente curricular se estabelece (na escola ou fora dela) enquanto prática pedagógica que visa um trabalho formativo em suas dimensões motoras, afetivas, sociais, culturais e cognitivas.

O que parece faltar para a formação e atuação profissional em Educação Física é uma reflexão que dê conta de problematizar as consequências desse processo de culturalização sobre a materialização de corpos distintos. Acreditamos que os estudos pós-estruturalistas e a perspectiva queer podem propor reflexões para que um debate nessa escala seja estabelecido. Argumentamos que o gênero deve ser compreendido enquanto um regime de verdade que fabrica corpos específicos para atenderem as demandas políticas de determinado meio. Dentre estas, a heterossexualidade é enaltecida enquanto forma legítima de expressão de vida, fato corroborado pelas práticas discursivas da Educação Física a partir da não problematização de seus conteúdos enquanto base constituinte de corpos/subjetividades atendentes a heteronormatividade.

\section{ESCOLA, HOMOSEXUALIDADES Y HOMOFOBIA: REMEMORANDO EXPERIENCIAS EN LA EDUCACIÓN FÍSICA ESCOLAR}

\section{Resumem}

Anclado en los estudios de género y queers nosotros analizamos cómo la homosexualidad etiquetado social, se lleva a cabo a través de las clases de Educación Física. Presentamos seis entrevistas semi-estructuradas con jóvenes adultos que autorreconheceram como homosexuales. Las sexualidades no heterosexuales son estigmatizados y se insertan en jerarquías, donde los hombres gay están sujetos a las manifestaciones de perjuicio que negativizam sus expresiones. La comprensión de las prácticas corporales en la perspectiva dicotómica de género, tales como 
ESCOLA, HOMOSSEXUALIDADES E HOMOFOBIA: REMEMORANDO EXPERIÊNCIAS NA EDUCAÇÃO FÍSICA

ESCOLAR

deportes, reitera el proceso de construcción cultural de la masculinidad y feminidad, relegado a la homosexualidade en la esfera de "ininteligibilidades" sociales.

Palabras clave: Educación Física Escolar; Homosexualidades; Homofobia

\title{
SCHOOL, HOMOSSEXUALIDADES AND HOMOPHOBIA: REMEMBERING EXPERIENCES IN SCHOOLAR PHYSICAL EDUCATION
}

\begin{abstract}
Anchored in gender and queer studies we aims to analyze the social labeling of homosexuality through in physical education practices at school. We present reports from six semi-structured interviews with young adults, who self-recognized as homosexuals, regarding their experiences in physical education classes. Non-heterosexual sexualities are stigmatized and framed in hierarchical relationships where young homosexuals are constantly targeted by prejudice and have their expressions of preference negated. Understanding physical behaviors from a dichotomous gender perspective, such as in sports, reiterates the cultural process that constructs masculinity and femininity, thus relegating homosexuality to the sphere of social "unintelligibility".
\end{abstract}

Keywords: School Physical Education at School; Homosexuality; Homophobia

\section{REFERÊNCIAS}

BUTLER, Judith. Críticamente subversiva. In: JIMÉNEZ, Rafael Mérida (Org.). Sexualidades transgresoras: una antología de estudios queer. Barcelona: Icaria, 2002, p. 55-79.

CUNHA JÚNIOR, C. F.; MELO, V. A. Homossexualidade, educação física e esporte: primeiras aproximações. Movimento. Porto Alegre, ano III, n. 5, p. 18-24, 2 sem., 1996.

DEVÍS DEVÍS, J.; MIGUEL, J. F.; SPARKES, A. C. ?Qué permanece oculto del currículum oculto? Las identidades de género y de sexualidad em la Educación Física. Revista Iberoamericana de Educación. N. 39, p. 73-90, 2005.

DEVIDE, Fabiano Pries; VOTRE, Sebastião Josué. Doping e mulheres nos esportes. Rev. Bras. Cienc. Esporte. Campinas, v. 27, n. 1, p. 123-138, set., 2005. 
PRADO, V. M.; RIBEIRO, A. I. M.

DORNELLES, Priscila Gomes. A (hetero)normalização dos corpos em práticas pedagógicas da Educação Física escolar. 2013. 193 f. Tese (Doutorado em Educação), Universidade Federal do Rio Grande do Sul, Porto alegre.

GOELLNER, Silvana Villodre. A educação dos corpos, dos gêneros e das sexualidades e o reconhecimento da diversidade. Cadernos de Formação RBCE. Campinas, p. 71-83, mar., 2010.

HALBERSTAM, Judith. Masculinidad Femenina. Barcelona/Madrid: Egales, 2008.

LANCENET. Michel, do Vôlei Futuro, reclama de homofobia em jogo da Superiga. Disponível em: <http://www.lancenet.com.br/minuto/Michael-Volei-Futuro-homofobiaSuperliga_0_456554549.html>. Acesso em: 13 de junho de 2013.

MADLENER, Francis. $O$ discurso sobre a homossexualidade no universo escolar: um estudo no curso de Licenciatura em Educação Física. 2006. 140 f. Dissertação (Mestrado em Educação). Universidade Federal do Paraná, Curitiba.

MORAES E SILVA, Marcelo. Entre a ilha deserta e o arquipélago: mapeamentos e cartografias das percepções de professores (as) sobre as masculinidades produzidas nas aulas de Educação Física. 2008. 215 f. Dissertação (Mestrado em Educação). Universidade Federal do Paraná, Curitiba.

ROSA, Marcelo Victor. Educação Física e homossexualidade: investigando as representações sociais dos estudantes do Centro de Desportos/UFSC. 2004. 131 f. Dissertação (Mestrado em Educação Física). Universidade Federal de Santa Catarina. Centro de Desportos. Florianópolis.

ROSA, Rodrigo Braga Couto. Enunciações afetadas: relações possíveis entre homofobia e esporte. 2010. 215 f. Dissertação (Mestrado em Educação Física). Universidade Estadual de Campinas, Campinas.

. Homofobia e Esporte na produção da Educação Física brasileira (1979-2007). 2008. 54

f. Trabalho de conclusão de Curso (Licenciatura em Educação Física). Faculdade de Educação Física, Universidade Estadual de Campinas: Unicamp.

SANTOS, Luciene Neves. Corpo, gênero e sexualidade: educar meninas e meninos para além da homofobia. 2008. 136 f. Dissertação (Mestrado em Educação Física). Universidade Federal de Santa Catarina, Florianópolis.

Data de recebimento: 01/02/2016

Data de aceite: 07/03/2016 